\title{
Fermentation of Vegetable Juices by Lactobacillus Acidophilus LA-5
}

\author{
Lavinia Claudia Buruleanu, Magda Gabriela Bratu, \\ Iuliana Manea, Daniela Avram and Carmen Leane Nicolescu
}

Additional information is available at the end of the chapter

http://dx.doi.org/10.5772/51309

\section{Introduction}

Probiotics foods represent one of the largest sectors in functional food markets. Most of the available probiotic products are some form of dairy, despite the continuous growth of the non-dairy probiotic sector, with products like soy-based drinks, fruit-based foods, and other cereal-based products. Both non-dairy (in general) and soy-based probiotic products represent a huge growth potential for the food industry, and may be widely explored through the development of new ingredients, processes, and products. For this purpose, new studies must be carried out to: test ingredients, explore more options of media that have not yet been industrially utilized, reengineer products and processes, towards potentially meet the demands of lactose-intolerant and vegetarian consumers for new nourishing and palatable probiotic products [1].

Lactic acid bacteria are among the most important probiotic microorganisms typically associated with the human gastrointestinal tract. Traditionally, lactic acid bacteria have been classified on the basis of phenotypic properties, e.g. morphology, mode of glucose fermentation, growth at different temperatures, lactic acid configuration, and fermentation of various carbohydrates. However some species, like the so-called Lactobacillus acidophilus group and some bifidobacteria, are not readily distinguishable by phenotypic characteristics [2]. From the physiological point of view, Lactobacillus acidophilus strains were characterized as lactic acid bacteria with strictly homofermentative metabolism ( $>85 \%$ lactic acid). The hexoses are preferential fermented via Embden - Meyerhof - Parnas (EMP), (as the strains produce aldolase and phosphoketolase), and only then the pentoses and gluconate are fermented. LAB of the Lactobacillus acidophilus group as well as of the Bifidobacterium group isolated from the human faeces or intestine are thought to have beneficial effects on health being thus considered to be probiotic bacteria [3]. 
For use in food, important criteria for probiotics must be met, in particular that they should not only be capable of surviving passage through the digestive tract, by exhibiting acid and bile tolerance, but also have the capability to proliferate in the gut.

Probiotics must be able to exert their benefits on the host through growth and/or activity in the human body. Although generally recognised as safe a probiotic strains must be characterized by a set of tests that assure its safety to consumer $(1,2,3,5,6)$.

Inclusion of probiotic bacteria in fermented dairy products enhances their value as better therapeutic functional foods. However, insufficient viability and survival of these bacteria remain a problem in commercial food products. By selecting better functional probiotic strains and adopting improved methods to enhance survival, including the use of appropriate prebiotics and the optimal combination of probiotics and prebiotics (synbiotics), an increased delivery of viable bacteria in fermented products to the consumers can be achieved [5].

The fermentation of vegetable products, applied as a preservation method for the production of finished and half-finished food products, is considered as an important technology, though requiring more research, as a growing number of raw materials are being processed in this way by the food industry. The main reasons for this interest are nutritional, physiological and hygienic aspects of the process [6]. Thus, according to Kelwicka, (2010) [7], the fermentation of beetroot juice requires selected starter cultures made of LAB, naturally present in this vegetable although their number is usually very small. This makes them un-appropriate to, alone, conducting a fermentation that ensures satisfying sensory properties of the fermented juice, with improved health promoting activity.

Thus, probiotic juices represent an alternative to dairy products that suits consumers who don't want to eat dairy foods or are lactose intolerant. Adding probiotics to juices is more complex than formulating in dairy products where the bacteria can be easily added to other cultures.

Despite its potential for healthy products development, there is very little research activity addressing the fermentation of vegetable juices using probiotic bacteria.

\section{Materials and methods}

\subsection{Vegetables treatments}

Fresh vegetables (carrots, cucumbers, beetroot, white cabbage, red cabbage) were purchased from a retail market and specifically processed by removing the non-edible pieces. The raw material processing was made faster, because the possibility of contamination and proliferation of microorganisms in the products is very high in comparison with their intact counterparts (Lee, 2011). Using a domestic extractor the vegetables were turned into juice. The heating treatment of the juice, applied at $80^{\circ} \mathrm{C}$ with a view to destroy the undesirable microorganisms under the limit of detection, was followed by cooling at $40^{\circ} \mathrm{C}$. 


\subsection{Microorganisms and fermentation conditions}

The strain Lactobacillus acidophilus LA-5 from Christian Hansen (Romania) was used in this study.

The lyophilized culture was aseptically inoculated into the vegetable juices and vigorously homogenized for $15 \mathrm{~min}$, according to the producer's specification. The fermentation experiments were carried out using Erlenmeyer flasks containing $50 \mathrm{ml}$ of juice, without $\mathrm{pH}$ adjustment. The flasks were incubated statically in an incubator chamber at $37 \pm 0.2^{\circ} \mathrm{C}$. Sampling was taken at regular interval of times for physico-chemical and microbiological analysis.

The tested supplements were: L-cysteine hydrochloride monohydrate (Merck, Darmstadt, Germany), L-lysine hydrochloride (Merck), L-valine (Merck), L-leucine (Calbiochem, San Diego, CA, USA) and yeast extract (Merck). Cysteine, lysine, valine and leucine were separately added in quantity by $0.1 \%(\mathrm{w} / \mathrm{v})$ into carrot juice, while amounts by $0.2 \%(\mathrm{w} / \mathrm{v})$ were tested, also individual, in the case of the yeast extract and cysteine. A control sample without supplements was carried out for each experiment.

\subsection{Physico - Chemical analysis}

Metabolic activity of the strain LA-5 in the conditions mentioned above was evaluated based on the dynamics of $\mathrm{pH}$, respectively end products of fermentation. The $\mathrm{pH}$ values were measured with a HACH pH-meter. Lactic acid was determined using commercial kits (KDLATE from Megazyme International). The calculations were made with Megazyme MegaCalc $^{\mathrm{TM}}$ and expressed as g lactic acid/l. Reducing sugars were analyzed applying the spectrophotometric method with 3.5-dinitrosalicilic acid (DNS) after the removing of other substances with reducing character using basic lead acetate and expressed as glucose/l. Ascorbic acid was determined applying the 2,6-dichloroindophenol titrimetic method, based on the reduction of the sodium salt of the dye by ascorbic acid (AOAC method). It was expressed as $\mathrm{mg} / 100 \mathrm{ml}$. The amino acids content, expressed as g glycine $/ 100 \mathrm{ml}$, was determined through the Sörensen method.

\subsection{Microbiological analysis}

The amount of viable cells of Lactobacillus sp. was determined by serial tenfold dilution with sterile peptone water. Aliquots of $1 \mathrm{ml}$ were plated, in duplicate, in plates with Man-RogosaSharpe agar, enriched with L-cysteine $\mathrm{HCl}$. The Petri plates were incubated for $48-72 \mathrm{~h}$ at $37^{\circ} \mathrm{C}$ and the results were expressed as log colony forming units (CFU)/ml juice.

The optical density of biomass was measured with the UV-Visible spectrophotometer at $610 \mathrm{~nm}$. In the preparation of the calibration curve for optical density vs. dry cell weight several dilutions of the juices were made. According Altiok [8], for each dilution $2 \mathrm{ml}$ of sample was used to obtain optical densities at $610 \mathrm{~nm}$ wavelength and $15 \mathrm{ml}$ of sample was filtered with a pre-weighed cellulose acetate membrane filter having a pore size of $0.45 \mu \mathrm{m}$ 
using a vacuum pump. The biomass collected on the filters was washed with $15 \mathrm{ml}$ of water and the filters were dried at $100^{\circ} \mathrm{C}$ for approximately $24 \mathrm{~h}$ until constant weight was observed. The results were expressed as $\mathrm{g}$.

\subsection{Statistical analysis}

Statistical analysis was carried out using the software SPSS (Statistical Package for the Social Science 17.0 trial version).

\section{Results and discussions}

\subsection{Effect of inoculum size on the lactic acid accumulation and biomass growth}

A comparative study of the dynamics of lactic acid fermentation of carrot juice using three different concentrations of lyophilized pure culture was realized (Figure 1).

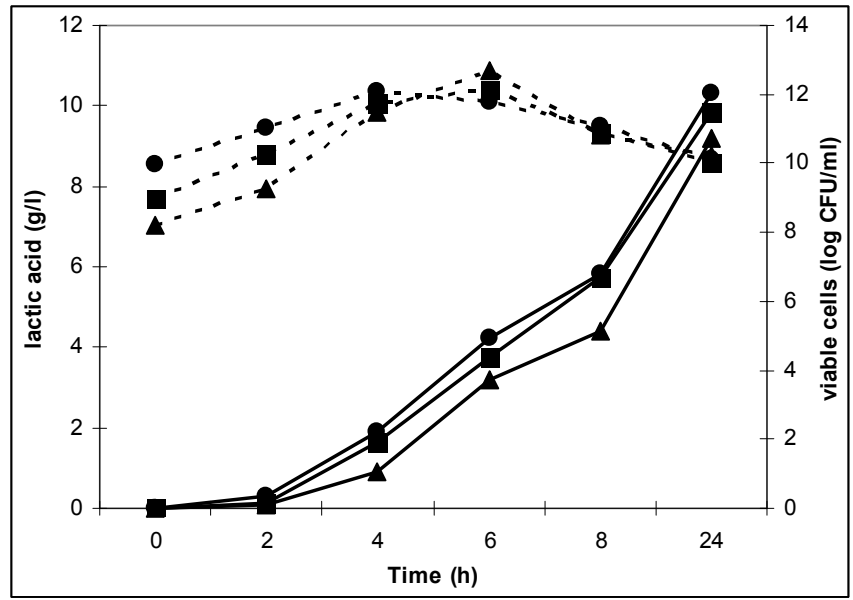

Figure 1. Correlation between lactic acid production by Lactobacillus acidophilus LA-5 and number of viable cells during fermentation of carrot juice with different inoculum size $\boldsymbol{\Delta} 0.2 \mathrm{~g} / \mathrm{l} ; \boldsymbol{\bullet} 0.3 \mathrm{~g} / \mathrm{l} ; \bullet 0.4 \mathrm{~g} / \mathrm{l}$ (smooth lines - lactate, dashed lines - viable cells count)

Relative higher differences concerning the lactate increasing were observed between the variant with $0.2 \mathrm{~g} / \mathrm{l}$ pure culture initial added and the other two within 24 hours of fermentation. Thus, at the end of this interval, the excess was by $7.06 \%$ in the juice with $0.3 \mathrm{~g} / \mathrm{l}$ inoculum and $12.06 \%$ in the juice with $0.4 \mathrm{~g} / \mathrm{l}$ inoculum respectively. However, in all the batches the lactic acid accumulation, higher than $9 \mathrm{~g} / \mathrm{l}$, could be considered satisfactory for the shelf life of the final products. From the other part, the number of viable cells is decisive for the probiotic feature of these ones. A direct proportionality between the amount of the lyophilised culture initial added and the viable cells was observed only in the first $4 \mathrm{~h}$ of the fermentation. As a general characteristic, in the interval $6-24 \mathrm{~h} \mathrm{pH}$ values less than 4.5 have become inhibitory for the useful microbiota in all the experimental samples. 
The initial concentration of reducing sugars of the carrot juices, by $25.2 \mathrm{~g} / \mathrm{l}$, was favourable for the growth of Lactobacillus acidophilus LA-5. Testing two strains of Lactobacillus (one genetically selected Mont4+ and the other genetically altered, Mont4+pxyAB-mod). Kiouss [9] established that the Mont4+ had the highest yield of lactic acid fermenting with six percent concentration of glucose, whereas the L strain utilized the sugar best at the four percent concentration. In the same time temperature and $\mathrm{pH}$ seemed to play the largest role in the organisms ability to grow and thus affecting its production of lactic acid.

Concluding, higher inoculum densities of Lactobacillus acidophilus LA-5 were not significantly influenced the survival yield of the useful microbiota in the lactic acid fermented juices after $24 \mathrm{~h}$. In the same time, no parallel relationships between lactic acid concentration and the inoculum size were determined. The result agrees to those obtained by Agarwal, Dutt, Meghwanshi and Saxena [10] using Enterococcus flavescens for production of lactic acid. In their opinion, beyond a certain concentration lactic acid yield dropped due to high cell density resulting in fast depletion of essential nutrients, limiting further growth and reducing the yield. Referring to bifidobacteria, Dave and Shah [11] reported also that a higher inoculum did not always improve their viability to a satisfactory level. No data referring to Lactobacillus acidophilus were found in the literature.

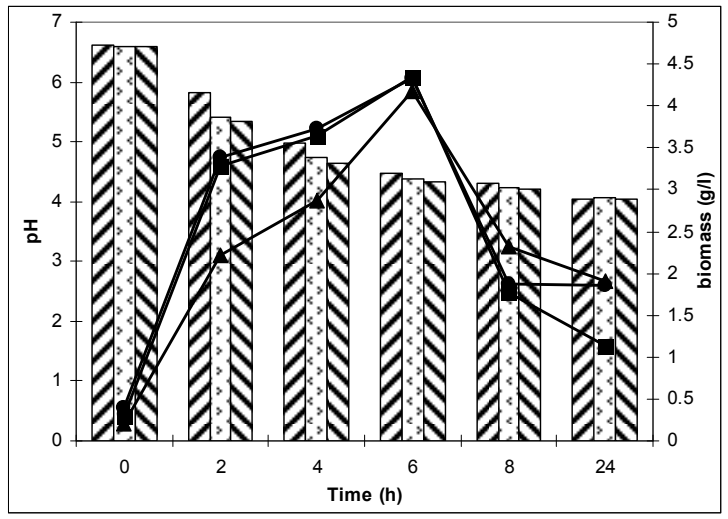

Figure 2. $\mathrm{pH}$ and biomass evolution during lactic acid fermentation of carrot juice with different inoculum of Lactobacillus acidophilus LA-5: $0.2 \mathrm{~g} / 1$ ( $\mathbf{Z Z 7}$ and $\mathbf{\Delta}$ ); $0.3 \mathrm{~g} / \mathrm{l}(\because \cdots$ and $\mathbf{m}) ; 0.4 \mathrm{~g} / \mathrm{l}(\mathbf{\mathbf { W }}$ and $\bullet$ ); columns - $\mathrm{pH}$ values, lines - biomass

Although the $\mathrm{pH}$ dynamics was quite different in the first $6 \mathrm{~h}$ of the process, the initial amount of the pure culture did not affect the subsequent evolution or the final value of this parameter (Figure 2).

The sharp decrease in biomass from 6 to $8 \mathrm{~h}$ has been correlated with the viable cells tendency, as result of reaching $\mathrm{pH}$ values by 4.34 to 4.47 . Being known that $L b$. acidophilus is more sensitive in acidic environment, this result underlines the necessity to manage the size of inoculum in order to obtain a balance between the lactic acid accumulation and the survival of the probiotic microorganisms. 
The maximum rate of acidification $v_{\max }$ was calculated as the time variation of $\mathrm{pH}(\mathrm{dpH} / \mathrm{dt})$ and expressed as $\mathrm{pH}$ units/min (Table 1). Other kinetic parameters were also calculated: time to reach $v_{\max }\left(t_{\max }\right.$, hours), time to reach $\mathrm{pH} 5.0$ ( $\mathrm{t}_{\mathrm{pH}}$ 5.0, hours), time to complete the fermentation ( $\mathrm{t}_{\mathrm{pH}} 4.2$, hours).

\begin{tabular}{|l|c|c|c|c|}
\hline Inoculum, g/1 & $\begin{array}{c}\text { Vmax } \cdot 10^{-3} \\
\text { (units/min.) }\end{array}$ & $t_{\max }(\mathrm{h})$ & $\mathrm{t}_{\mathrm{pH} 5.0}(\mathrm{~h})$ & $\mathrm{t}_{\mathrm{pH} 4.2}(\mathrm{~h})$ \\
\hline 0.2 & 7.08 & 4 & 2.95 & 8.4 \\
\hline 0.3 & 9.83 & 2 & 2.88 & 8.2 \\
\hline 0.4 & 10.41 & 2 & 2.67 & 8.05 \\
\hline
\end{tabular}

Table 1. 1. Acidification kinetic parameters of fermentation of carrot juices by Lactobacillus acidophilus LA-5

A double amount of inoculum had an insignificant influence on the time to reach $\mathrm{pH}$ 5.0, important parameter from the shelf life of the fermented juices. Thus, $\mathrm{t}_{\mathrm{pH}} 5.0$ (h) was 1.1-fold higher in the case of the batch with $0.2 \mathrm{~g} / 1$ lyophilized pure culture initial added to juice than that one with $0.4 \mathrm{~g} / \mathrm{l}$. A different situation was registered concerning the maximum rate of acidification $\left(V_{\max }\right)$ and the time to reach this rate $\left(t_{\max }\right)$. Thus, a polynomial equation of the form $y=-108.5 x^{2}+81.75 x-4.93$ correlated the size of inoculum with the corresponding values of $V_{\max }$ at $R$ squared $=1$. Although at the initial moment of fermentation seems to be advantageous to use a higher amount of pure culture, this aspect lessen in time, from the economic point of view being important to obtain a balance between the quantity of inoculum and the targeted parameters which ensure the preservation of the final product.

The values of the biomass content became close after about $6 \mathrm{~h}$ of fermentation. No parallel relationship between lactic acid concentration and biomass was observed, result that agrees to those obtained by Amrane [12] and Kotzamanidis [13].

However, taking into account the lactic acid accumulation and the dynamics of the number of viable cells, it was obvious that the utilization of higher amount of inoculum is not justified.

\subsection{Effect of temperature on the dynamics of fermentation}

According to the information provided by the producer of the lactic culture, respectively to the data found in literature, two different incubation temperatures were tested: $37^{\circ} \mathrm{C}$ and $41^{\circ} \mathrm{C}$ respectively.

The dynamics of both $\mathrm{pH}$ and lactic acid (Figure 3) emphasizes the influence of the higher temperature on the rate of acidification. After $24 \mathrm{~h}$ no significant differences between the $\mathrm{pH}$ values were determined, while the lactic acid content of the samples fermented at $41^{\circ} \mathrm{C}$ was 1.24 -fold higher comparatively with those fermented at $37^{\circ} \mathrm{C}$. This situation may be due to the higher amino acids content in the samples fermented at $41^{\circ} \mathrm{C}$, that act as buffer. Thus, expressed as glycin, the total amount was by $0.165 \mathrm{~g} / 100 \mathrm{ml}$ at the end of the analyzed interval, which represented an increase by $10 \%$ comparatively with the batch fermented at lower temperature. 


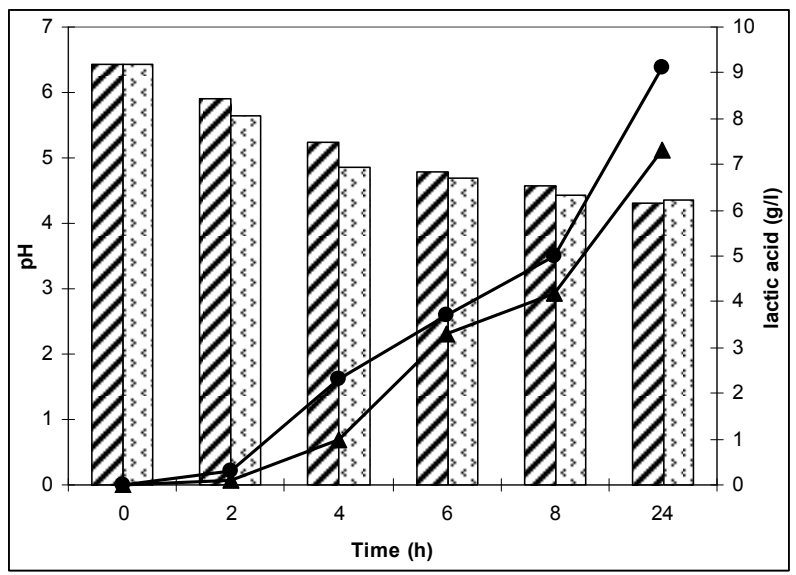

Figure 3. $\mathrm{pH}$ and lactic acid dynamics during the lactic acid fermentation of carrot juice at different temperatures: $37^{\circ} \mathrm{C}(\mathbf{Z Z Z}$ and $\mathbf{\Delta})$ and $41^{\circ} \mathrm{C}(\cdots \cdot 3$ and $\bullet$ ); columns - $\mathrm{pH}$ values, lines - lactic acid content

The rate of acidification has been correlated with the glucose consumption: $38.9 \%$ in the case of the juice fermented at $37^{\circ} \mathrm{C}$, respectively $53.89 \%$ in the case of the juice fermented at $41^{\circ} \mathrm{C}$. The different tendency of this parameter became obviously after $4 \mathrm{~h}$ of fermentation (Figure 4), being the consequence of the different rate of growth of Lactobacillus acidophilus, expressed as optical density at $610 \mathrm{~nm}$.

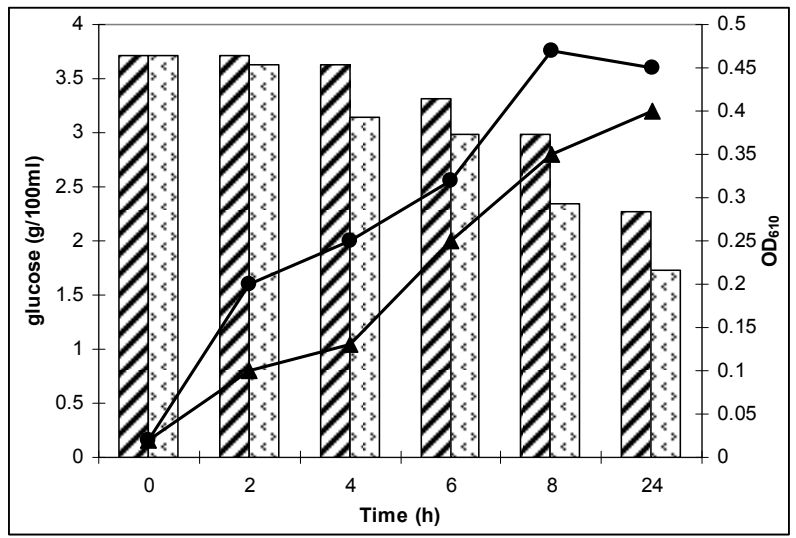

Figure 4. Glucose consumption and microbial evolution during the lactic acid fermentation of the carrot juices at different temperatures: $37^{\circ} \mathrm{C}(\mathbf{Z Z Z}$ and $\mathbf{\Delta})$ and $41^{\circ} \mathrm{C}(\cdots \rightarrow$ and $\bullet$ ); columns - glucose, lines optical density at wavelength by $610 \mathrm{~nm}$

Although close, the yields of glucose conversion to lactic acid have inclined the balance in favour of the juices fermented at $37^{\circ} \mathrm{C}$, the corresponded value being by 0.5 , unlike 0.45 in the case of the juices incubated at $41^{\circ} \mathrm{C}$. 
The faster consumption of the carbon source, correlated with the growth of the useful microbiota at higher temperature, respectively with the increase of the lactic acid content until the value by $9.1 \mathrm{~g} / \mathrm{l}$, was followed at $24 \mathrm{~h}$ by the decline of the viability of Lactobacillus acidophilus. Taking into account the dynamics of all the above mentioned parameters, the incubation temperature applied in the further studies was by $37 \pm 0.1^{\circ} \mathrm{C}$.

\subsection{The behaviour of different raw materials during the lactic acid fermentation by Lactobacillus acidophilus LA-5}

Fresh white cabbage (Brassica oleracea L.), red cabbage (Brassica oleracea var. capitata f. rubra), red beet (Beta vulgaris var. vulgaris), cucumbers (Cucumis sativus) and red onion (Allium cepa var. ascalonicum) were chosen in order to perform different experimental batches, as follows: $\mathrm{Cb}$ - cabbage juice, $\mathrm{RCb}$ - red cabbage juice, $\mathrm{Rb}$ - red beet juice, $\mathrm{Cc}$ - cucumber juice, $\mathrm{CcO}$ cucumber juice with $0.1 \%(\mathrm{v} / \mathrm{v})$ onion juice added after the heating and cooling of the batches.

$\mathrm{pH}$ and lactic acid dynamics during the lactic acid fermentation of vegetable juices with $L b$. acidophilus are shown in Figure 5 and Figure 6 respectively. The $\mathrm{pH}$ values ranged from 6.29 to 3.74 , no significant differences between the analyzed batches being observed, excepting the red beet juice. Thus, after one day a higher value by 4.28 was determined, the prolongation of the time of fermentation with other $24 \mathrm{~h}$ hadn't a positive influence on this parameter.

After 24h, the highest decrease of $\mathrm{pH}$ was determined in the case of the cucumber juice (2.51 units), correlated with the increase of the lactic acid amount until 9.36g/l. Although the $\mathrm{pH}$ values of the samples $\mathrm{Cc}$ and $\mathrm{Cb}$ were close during the process development, the maximum rate of acidification $V_{\max }$ registered a better value of $9.33 \cdot 10^{-3}$ units $/ \mathrm{min}$. in the case of the cucumber juice. This could explain the fermentation slowdown in the batch $\mathrm{Cb}$ the interval $6-8$ hours. Correlated with the results of the microbiological analysis, it seems that this time the process was directed towards the growth of the useful microbiota. A minimum value of the maximum rate of acidification, by $6.66 \cdot 10^{-3}$ units $/ \mathrm{min}$., was determined in the case of $\mathrm{CcO}$, while the time to reach $\mathrm{pH} 5.0$ ( $\mathrm{t}_{\mathrm{pH}}$ 5.0, hours) ranged between $1.9(\mathrm{Cb})$ to $3.5(\mathrm{CcO})$.

A relative distinct behaviour was observed in the case of red cabbage juice, red beet juice and cucumber juice with onion juice added, in the sense of the slowdown of the metabolism objectified in the dynamics of the parameters that describe the process unfolding. The differences could be explained through the presence of some chemical constituents which can act as inhibitors on useful bacteria, like anthocyanins in the red cabbage, betacyanins in red beet, respectively constituent sulfides in the onion juice. According [14], sulfides, especially those with three or more sulfur atoms, apparently possess potent antimicrobial activity. However, concerning the batch with onion juice added the initial trend was attenuated after 6 hours of fermentation, the oils and their sulfides constituent showing weak antimicrobial activity ([15]). 


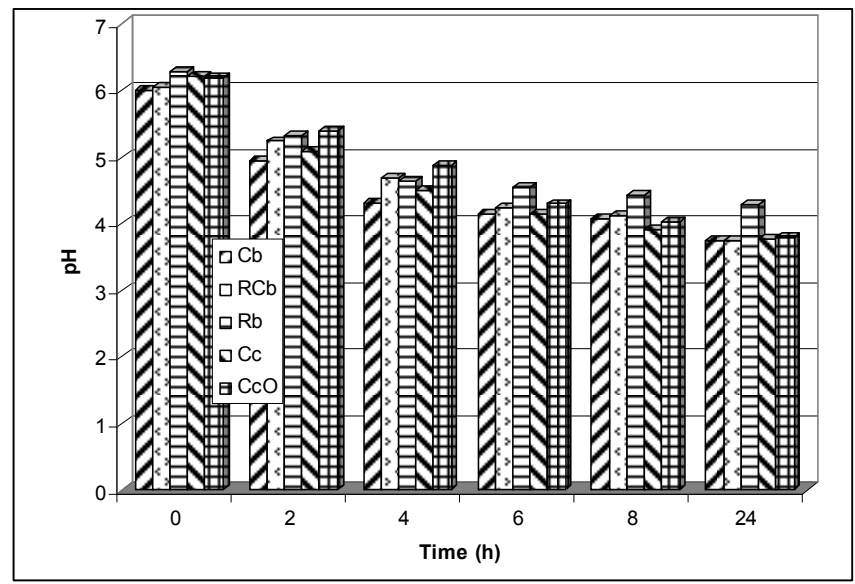

Figure 5. $\mathrm{pH}$ dynamics in vegetable juices obtained from different raw materials, during fermentation with Lactobacillus acidophilus LA-5

Referring to the red cabbage juice, although after 24 hours of fermentation the $\mathrm{pH}$ values were similar, the lactic acid content was lesser with about $1.5 \mathrm{~g} / \mathrm{l}$ compared with the white cabbage juice. This can be due to the amphoteric nature of the anthocyanins.

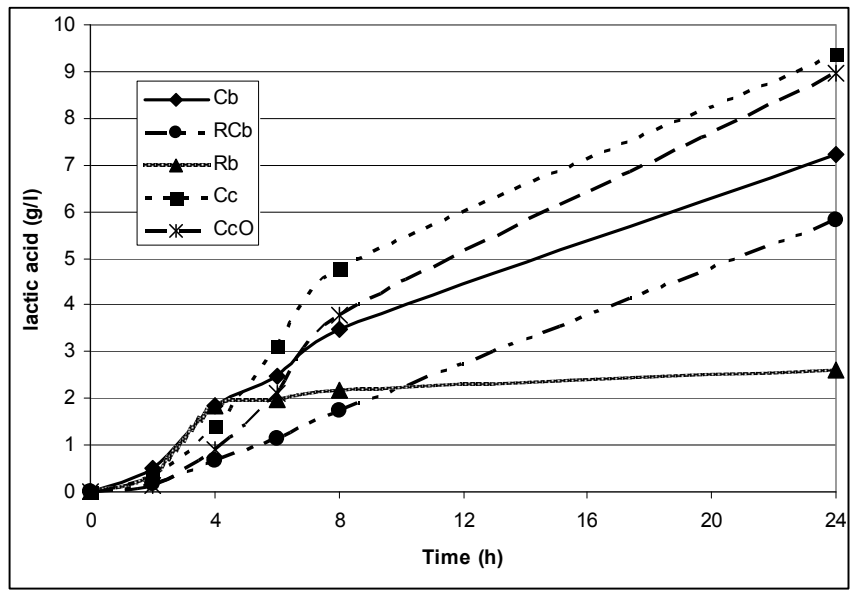

Figure 6. Lactic acid accumulation in vegetable juices obtained from different raw materials, during fermentation with Lactobacillus acidophilus LA-5

[16] studied the fermentation of cucumber juices with a $0.5 \%, 1 \%$ and $2 \%$ additions of the onion juices by $L b$. plantarum CCM 7039. It was found that in the initial stages of fermentation, the presence of onion in the juices positively influenced lactic and acetic acid production. However, in further course of fermentation, slight inhibition effects of onion in the fermented juices were observed, especially at elevated onion/cucumber ratio. 
The correlation between the biomass amount and the production of lactic acid (Figure 7) in the case of lactic acid fermentation of red beet juices with Lactobacillus acidophilus in the first 24 hours, was described using the Luedeking \& Piret model [17]. According to this model, the instantaneous rate of lactic acid formation $(\mathrm{dP} / \mathrm{dt})$ can be related to the instantaneous rate of bacterial growth $(\mathrm{dN} / \mathrm{dt})$, and to the bacterial density $(\mathrm{N})$, throughout fermentation at a given $\mathrm{pH}$, by the expression:

$$
d P / d t=\alpha d N / d t+\beta N
$$

where the constants $\alpha$ and $\beta$ are determined by the $\mathrm{pH}$ of the fermentation.

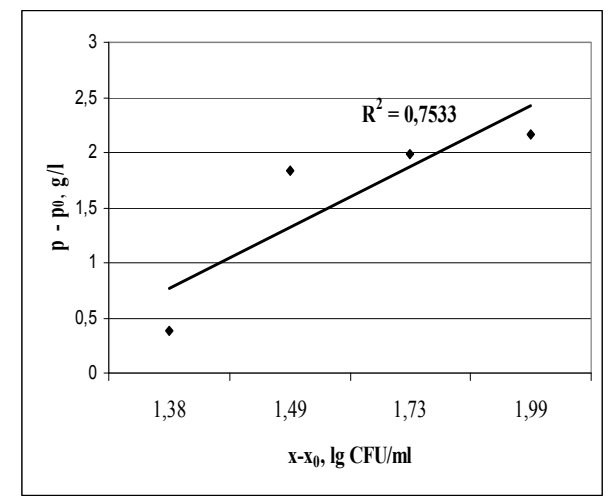

Figure 7. The correlation between the lactic acid production and viable cells count of Lactobacillus acidophilus LA-5 growing on red beet juices

A simplified presentation of the above model relates to the linear part of the equation which is presented as:

$$
\left(p-p_{0}\right)=\alpha\left(x-x_{0}\right)
$$

where $p_{0}$ and $p$ are the concentrations of lactic acid (g/l) initially and at time $t$, respectively, and $x_{0}$ and $x$ are the increases of the biomass $(\log \mathrm{CFU} / \mathrm{mL})$ initially and at time $t$, respectively.

The R squared coefficient closed by the ideal value " 1 " $\left(R^{2}=0.9989\right)$ in the case of the carrot juices fermented with Lactobacillus acidophilus LA-5 (data not shown) highlights a better linear correlation, respectively a strong connection between the lactic acid production and the lactic acid bacteria growth. Not the same situation has registered in the lactic acid fermentation of the red beet juices with the same strain. The highest value of the coefficient $\left(1-R^{2}\right)$ it is caused by the increase of the lactic acid amount in the first 4 hours, followed by a steady interval of evolution of this parameter. From the other hand, according [18], the deviations from the linear dependence are mostly caused by nutritive limitations of the substrates, and are related to the specific bacterial species. Not at least, the initial content of reducing sugars of the red beet, by $21.2 \mathrm{~g} / \mathrm{l}$, could be limiting. However, taking into account 
the fact that the cucumber juice underwent a tumultuous fermentation although its content was only with $15.09 \%$ higher, it seems that other chemical constituents of the raw materials are responsible for the above mentioned differences.

The initial content of sugars in cucumber juice was situated at the maximum limit determined by [19], while in the case of the white cabbage juice was close to that one determined by [20].
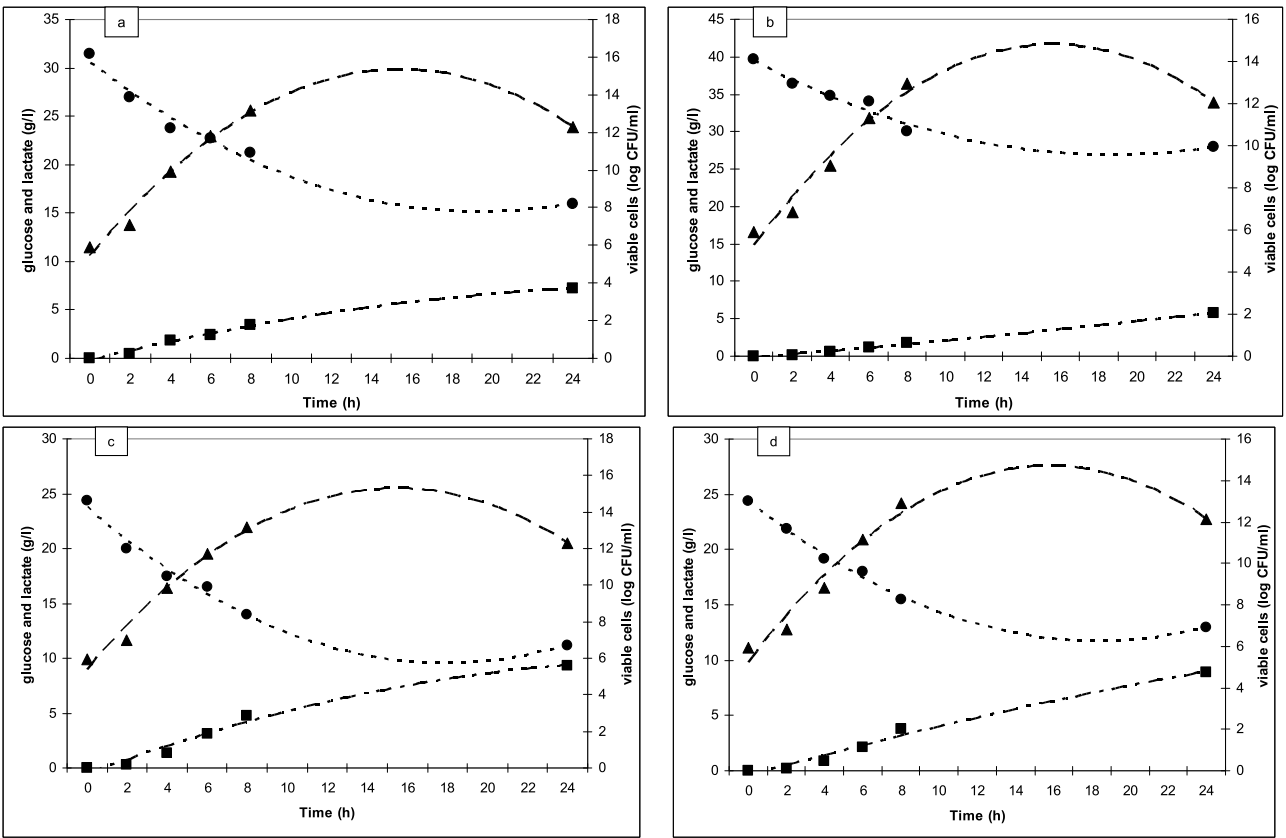

Figure 8. Correlation between the substrate consumption, lactate production and viable cells $\mathrm{Cb}(\mathrm{a})$, $\mathrm{RCb}(\mathrm{b}), \mathrm{Cc}(\mathrm{c})$ and $\mathrm{CcO}(\mathrm{d})$

- - glucose, $\mathbf{\square}$ - lactate, $\boldsymbol{\Delta}$ - viable cells (points - experimental data, smooth lines - predicted values)

The metabolization of the reducing sugars after $24 \mathrm{~h}$ of lactic acid fermentation of vegetable juices with $\mathrm{Lb}$. acidophilus LA-5 ranged between $26.66 \%(\mathrm{Rb})$ to $54.09 \%(\mathrm{Cc})$. Relative close values were obtained by other authors in lactic acid fermentation of vegetable juices. Thus, the utilization of sugar during fermentation in a mixture of beetroot juice and carrot juice and different content of brewer's yeast autolysate with $L b$. plantarum A112 and with $L b$. acidophilus NCDO 1748 varied from 19.4 to $24.1 \%$ ([21]).

The tested pure culture, routinely used for dairy products, was found to be capable of growing on pure vegetable juices without nutrients added. In the batches obtained from cabbage, respectively cucumber, the maximum volumetric productivity was determined after 8 hours as follows: $19.25 \times 10^{14} \mathrm{CFU} /(1 \cdot \mathrm{h})$ for $\mathrm{Cb}, 11.9 \times 10^{14} \mathrm{CFU} /(\mathrm{l} \cdot \mathrm{h})$ for $\mathrm{RCb}, 18.6 \times 10^{14}$ $\mathrm{CFU} /(1 \cdot \mathrm{h})$ for $\mathrm{Cc}$ and $10.25 \times 10^{14} \mathrm{CFU} /(1 \cdot \mathrm{h})$ for $\mathrm{CcO}$ respectively. 
Lactic acid is the major metabolite of Lactobacillus acidophilus, influencing both the preservation of the fermented products and the sensorial characteristics of these ones. The effect of the amino acids and of the yeast extract on the dynamics of the lactic acid, assessed against the control, is underlined through the data from Table 3. The buffering capacity of the amino acids prevented a direct proportionality between the $\mathrm{pH}$ values and the lactic acid content.

\begin{tabular}{|l|c|c|c|c|c|c|}
\hline Time, $h$ & Cys_1 & Leu & Val & Lys & Cys_2 & YE \\
\hline 2 & 8.737864 & -12.6214 & 21.52778 & -29.8611 & 107.6923 & 15.38462 \\
\hline 4 & 17.66784 & -23.6749 & -5.55556 & -2.77778 & 28.125 & 12.5 \\
\hline 6 & 16.98113 & -1.50943 & 11.71717 & 3.636364 & 1.818182 & 5.454545 \\
\hline 8 & 20.63492 & -1.5873 & 8.571429 & 1.428571 & -11.1111 & 15.87302 \\
\hline 24 & 0.925926 & -0.92593 & 5.076142 & 4.568528 & -14.433 & 11.34021 \\
\hline
\end{tabular}

Table 3. Time-increasing of lactic acid during $24 \mathrm{~h}$ of lactic acid fermentation of carrot juices by Lactobacillus acidophilus LA-5

The values were expressed in percents by reporting the difference between sample and control to the control, at the same moment of time

Negative values shows that for the corresponding interval of time the supplements had not influence on the lactic acid production at the used levels.

Analyzing the whole process, only the samples with a minimum amount of cysteine added and those with yeast extract have been a great effect on the time-increasing of lactic acid. At the other opposite were found the samples with leucine added, this amino acid with nonpolar hydrophobic chains clumsying the fermentation. From the viewpoint of increase the lactic acid content in the final stages of the process, the supplementation of the carrot juices with $0.2 \%(\mathrm{w} / \mathrm{v})$ cysteine seems to be undesirable.

The beneficial effect of cysteine on the lactic acid accumulation in vegetable juices can occur due to its buffering capacity, which may diminish the toxic effects of organic acids on lactobacilli. Referring to the yeast extract, which contains more cell growth factors, being used generally as a source of assimilable nitrogen, vitamins and minerals, its influence at the level of $0.2 \%(\mathrm{w} / \mathrm{v})$ on the time-increasing of lactic acid could be characterized as moderate. If some authors reported different maximum lactic acid concentration in media supplemented with yeast extract, several possible explanations include the strain of microorganism, the chemical composition of the substrate, the fermentation system, and generally the conditions employed during fermentation ([12]).

Effect of supplements on the performance of lactic acid production was evaluated based on lactic acid productivity and lactic acid yield, respectively on glucose ratio (Table 4).

The previous conclusion referring to the positive influence of the yeast extract and cysteine (in minimum amount) on the development of the lactic acid fermentation of vegetable juices is confirmed by the data from Table 4 . Good values of lactic acid productivity were obtained 
after $24 \mathrm{~h}$ of fermentation in the samples with valine and lysine added, although in these ones the substrate consumption seems to be directed to the increasing of biomass, aspect emphasized by the average values of the lactic acid yield.

\begin{tabular}{|l|c|c|c|c|c|c|}
\hline Parameter & Cys_1 & Leu & Val & Lys & Cys_2 & YE \\
\hline Lactic acid yield ${ }^{2)}$ & 1.1 & 0.85 & 0.88 & 0.79 & 0.85 & 1.15 \\
\hline $\begin{array}{l}\text { Lactic acid } \\
\text { productivity }^{3)}\end{array}$ & 1.01 & 0.99 & 1.06 & 1.05 & 0.7 & 1.13 \\
\hline $\begin{array}{l}\text { Glucose conversion } \\
\text { ratio }^{4}\end{array}$ & 1.1 & 0.9 & 1.2 & 1.05 & 0.92 & 1.25 \\
\hline
\end{tabular}

1)The data from the table were obtained by dividing the corresponding values for the samples to those of the control ${ }^{2}$ Lactic acid yield was calculated by dividing the amount of lactic acid produced to the amount of glucose consumed ${ }^{3}$ Lactic acid productivity was defined as the amount of lactic acid produced per hour per liter ${ }^{4}$ Glucose conversion ratio was calculated by dividing the amount of glucose consumed to the initial amount of glucose.

Table 4. Effect of supplements on lactic/acetic acid production after $48 \mathrm{~h}$ of fermentation ${ }^{1)}$

The effect of supplements (amino acids and yeast extract) on the ascorbic acid dynamics is shown in Figure 9. L-Ascorbic acid (AA), also known as vitamin C, is a representative watersoluble vitamin possessing a variety of biological, pharmaceutical, and dermatological functions; it promotes collagen biosynthesis, provides photoprotection, causes melanin reduction, scavenges free radicals, and enhances immunity ([23]).

Due to the heat treatment applied with a view to destroy the epiphytic microbiota of the fresh vegetable juices, the losses occurred in the ascorbic acid content represented about $65 \%$.

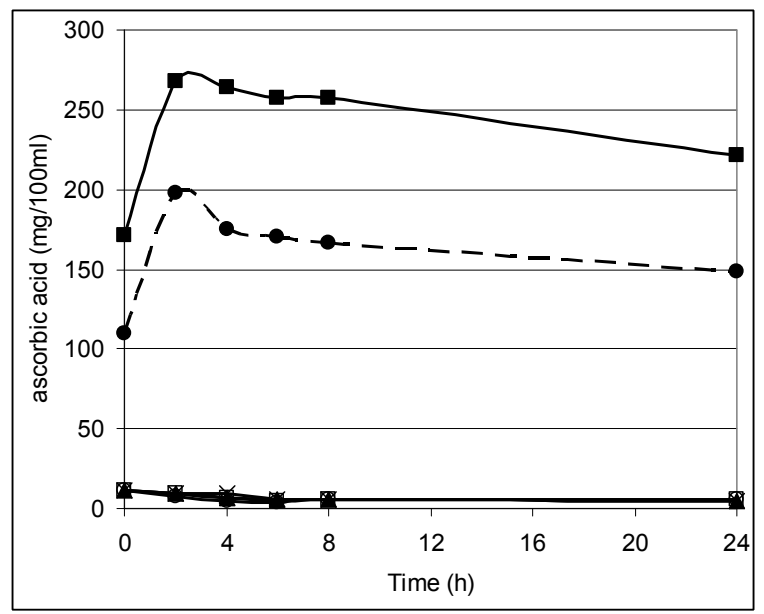

Figure 9. Time-course (0-24h) of the relative levels of ascorbic acid $(\bullet$ Cys_1, $\bullet$ Cys_2, ○YE, $\square$ Leu, $\boldsymbol{\Delta}$ Val, x Lis). The data shown are average values of two independent replicate experiments 
The presence of ascorbic acid into vegetable juices submitted to fermentation by probiotic bacteria, especially by Lactobacillus acidophilus strains, is desired not only from the nutritional point of view, but also due to the fact that it could promote anaerobic conditions, acting as an oxygen scavenger. [24] have shown also that the fruit juices may be an alternative vehicle for the incorporation of probiotics because they are rich in nutrients and do not contain starter cultures that compete for nutrients with probiotics. Furthermore, fruit juices are often supplemented with oxygen scavenging ingredients such as ascorbic acid, thus promoting anaerobic conditions.

L-cysteine, a sulfur-containing amino acid known as a powerful reducing agent, caused the reduction of dehydroascorbic acid to ascorbic acid, which led a different behavior of the samples Cys_1 and Cys_2 by the others. The increase of this parameter was by $80 \%$ and $56.4 \%$ respectively, after $2 \mathrm{~h}$ from the initial moment of fermentation. Subsequently, the analyzed parameter had the same diminishing tendency as in the other batches.

The losses occurred after $24 \mathrm{~h}$ of lactic acid fermentation of carrot juices with Lactobacillus acidophilus LA-5 ranged from $48.39 \%$ (YE) to $61.9 \%$ (control). The possible reason could be the oxygen traces that cause the chemical oxidation of the vitamin C.

In order to evaluate the probiotic feature of the vegetable juices, the study of the effect of supplements on Lactobacillus acidophilus growth is from overwhelming importance, both during the lactic acid fermentation and during the storage of the final products.

Between the analyzed samples, those with yeast extract and $0.1 \%(\mathrm{w} / \mathrm{v})$ cysteine added registered a higher increase of the number of viable cells till $14.4-14.5 \log \mathrm{CFU} / \mathrm{ml}$ in the first $8 \mathrm{~h}$ of the process. Concerning the yeast extract, the most possible explanation is due to an enhanced availability of minerals, which are growth promoters for L. acidophilus ([25]), while discussing the factors that affect the activity of endogenous probiotics, (26) mentioned that some of the growth promoters in cow milk were apparently cysteine-containing peptides.

Referring to the juices with leucine, lower values were determined comparative with the control during $24 \mathrm{~h}$, while in the samples with $0.2 \%(\mathrm{w} / \mathrm{v})$ cysteine added the trend of the survival of lactobacilli was slow down in the period $6-8 \mathrm{~h}$, the level being by 13.5 and 13.6 $\log \mathrm{CFU} / \mathrm{ml}$ respectively. The last observation agrees with this one of [27], which have shown that the increasing of cysteine concentration improved the viability of B. bifidum in bio-yogurt, although it had no important effect on the viability of Lactobacillus acidophilus.

The batches supplemented with valine and lysine had occupied an intermediate position, the growth until $14.2 \log \mathrm{CFU} / \mathrm{ml}$ after $8 \mathrm{~h}$ of fermentation making from the utilization of these amino acids a promising variant in the future, with a view to optimize the conditions of the process unfolding. In the period 8 - $24 \mathrm{~h}$ the number of viable cells decreased, as result of the lack of tolerance at lower $\mathrm{pH}$ of the analyzed strain.

The correlation between the most important parameters of the lactic acid fermentation of the carrot juices with Lactobacillus acidophilus LA-5 were evaluated using Pearson correlation analysis (significance level $p<0.01$; confidence level of 99\%). 


\begin{tabular}{|l|c|c|c|c|c|c|}
\hline $\begin{array}{l}\text { Analytical } \\
\text { variables }\end{array}$ & $\mathrm{pH}$ & $\begin{array}{c}\text { lactic } \\
\text { acid }\end{array}$ & glucose & viable cells & glycine & $\begin{array}{c}\text { ascorbic } \\
\text { acid }\end{array}$ \\
\hline $\mathrm{pH}$ & 1 & $-0.889^{* *}$ & $0.829^{* *}$ & $-0.940^{* *}$ & $0.099^{*}$ & $-0.184^{*}$ \\
\hline lactic acid & & 1 & $-0.891^{* *}$ & $0.843^{* *}$ & $-0.201^{*}$ & $0.016^{*}$ \\
\hline glucose & & & 1 & $-0.789^{* *}$ & $0.093^{*}$ & $0.084^{*}$ \\
\hline viable cells & & & & 1 & $-0.061^{*}$ & $0.066^{*}$ \\
\hline glycine & & & & & 1 & $-0.103^{*}$ \\
\hline ascorbic acid & & & & & & 1 \\
\hline
\end{tabular}

** Correlation is significant at the 0.01 level (2-tailed)

* Not significant

Table 5. The Pearson coefficients for the experimental batches

The correlations are strong between $\mathrm{pH}$ and lactic acid, respectively $\mathrm{pH}$ and glucose, while a very strong relationship $\mathrm{pH}$ - viable cells could be considered (Table 5). A non-existent relationship between ascorbic acid / amino acids content (expressed as glycine) and the other analyzed parameters was determined.

A firm correlation between glucose and lactic acid was expected, but on the one hand it is known that the practical yield of sugars conversion to lactic acid of the strains of the group Lb. acidophilus is about $85 \%$, while on the other hand the analysis does not include supplementary data referring to other factors that might be involved in the dynamics of the lactic acid fermentation of vegetable juices.

Factor Analysis (FA) is a multidimensional statistic method whose purpose is the analysis of the structure of mutual dependences of variables. The method is similar to the Principal Component Analysis (PCA) with the exception of the factor weights that are scaled ([28]).

Applying FA to the experimental data, the analytical variables were reduced to two principal components, which accounted for $59.72 \%$ (PC1) and respectively $18.95 \%$ (PC2) from the total variance. According to the component matrix, respectively to the values of the component loadings expressed by the first second principal components (rotation method: Varimax with Kaiser normalization), the most notable variables were $\mathrm{pH}$ and lactic acid (equal loading values by 0.954 ). Higher values were obtained also for viable cells (loading 0.939 ) and glucose (loading 0.933).

The combination of PC1 and PC2 (Figure 10) underlined the lack of correlation between amino acids content / ascorbic acid and all the other parameters taking into account both control and supplemented samples. While PC1 affected the dependent and independent variables involved in the progress of the lactic acid fermentation of vegetable juices, respectively in their probiotic feature, PC2 separated the variables which contribute to the nutritional characteristics of the final products. 


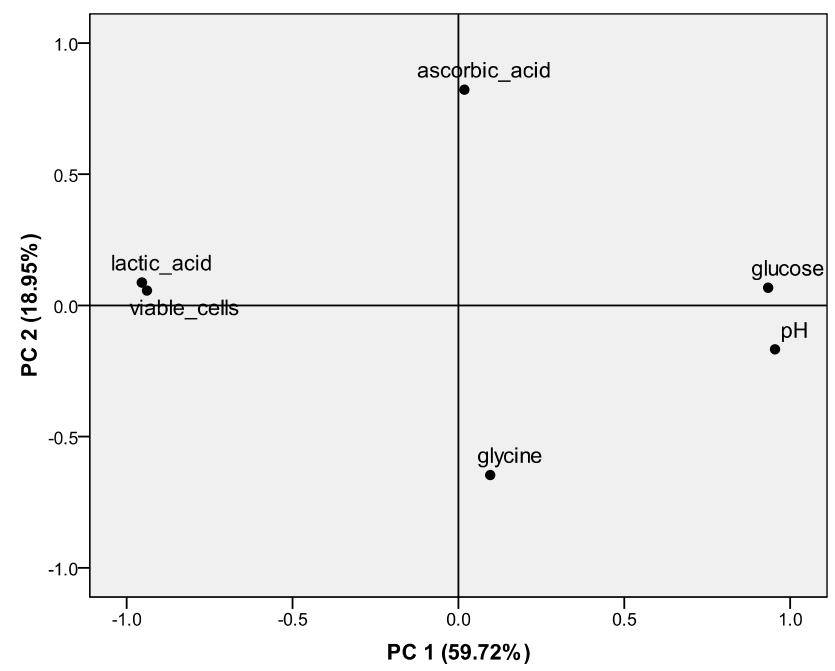

Figure 10. Component plot in rotated space

Applying PCA to the lactic acid fermentation of cabbage juices with various microorganisms, [29] established that the original 7 analytical variables were reduced also to 2 independent components that explained $88.2 \%$ from total variance of input data (PC1 $66.9 \%$ and PC2 21.3\%).

Cluster Analysis (CA) is a statistic method whose purpose is to join data into clusters with a view to increase their withingroup homogeneity. Usually, the FA is considered the first step of CA, with a view to reduce the data dimensionality. In order to better distinguish among experimental samples, the cluster method of the nearest neighbour was used. The distances between objects were measured as squared Euclidean distance. K-Means Cluster Analysis divided the experimental data into three groups, characterized by similar analytical properties, as follows:

- cluster 1: all the carrot juices (control samples and the batches with amino acids and yeast extract added) at the initial moment of fermentation, respectively at $2^{\text {th }} \mathrm{h}$ of fermentation. Supplementary, this cluster included the control and the sample with leucine at $4^{\text {th }} \mathrm{h}$ of fermentation (C_4 and Leu_4);

- $\quad$ cluster 2: all the carrot juices at $24^{\text {th }} \mathrm{h}$ of fermentation and the sample with lysine added at $8^{\text {th }} \mathrm{h}$ of fermentation ;

- $\quad$ cluster 3: the carrot juices with leucine and lysine added, respectively the control, at $6^{\text {th }}$ and $8^{\text {th }} \mathrm{h}$ of fermentation (Leu_6, Leu_8, Lys_6, Lys_8, C_6, C_8); the carrot juices with cysteine, valine, respectively yeast extract from $4^{\text {th }}$ to $8^{\text {th }} \mathrm{h}$ of fermentation (Cys_4 Cys_8, (Val_4 - Val_8), (YE_4 - YE_8). 


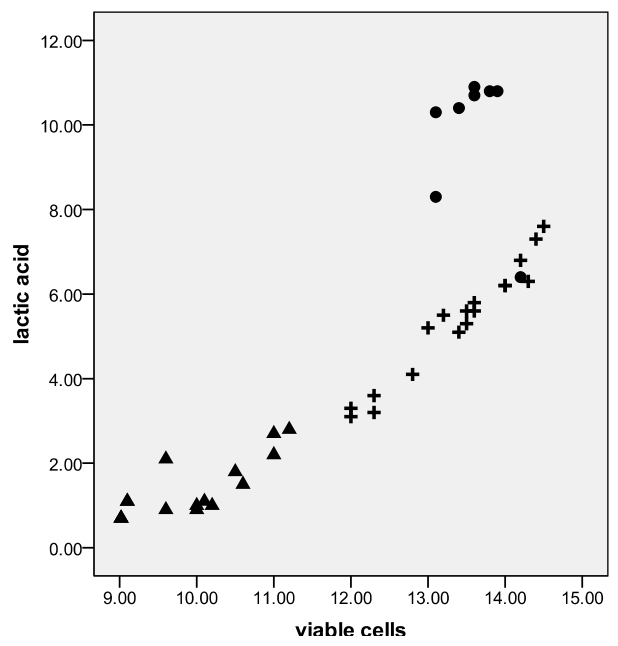

Cluster Number of

$$
\text { Case }
$$

$\Delta 1$

-2
+3

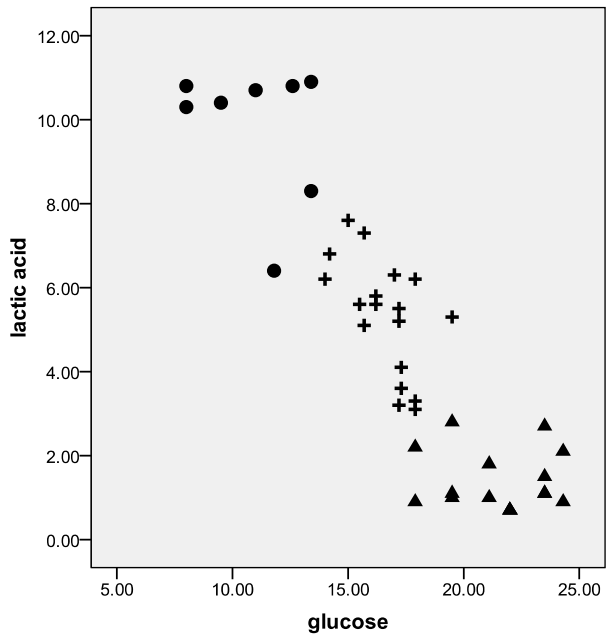

Cluster Number of

Case

$\Delta 1$

$+3$

Figure 11. Clusters plotting in coordinate of two selected variables: lactic acid - viable cells and lactic acid - glucose

The clusters in axes of two selected variables (Figure 11) denote that the samples from the first cluster were marked with a higher content of substrate, null or very lower lactate amount and $\mathrm{pH}$ values more than 5 . The corresponding time was both 0 and $2 \mathrm{~h}(\mathrm{C}, \mathrm{Val}, \mathrm{Leu}$, and YE) or the entire interval 0 - 4h (Leu and control).

The samples at the final moment of fermentation and those with lysine after $8 \mathrm{~h}$ of the process were included in the second cluster, characterized through lower or average values of glucose content, higher lactic acid amount and $\mathrm{pH}$ values close to 4.2. This cluster marks the achievement of the optimum characteristics of the lactic acid fermented products. 
The samples included in the third cluster best describes a vigorous process, being characterized through average values of the main parameters involved in the dynamics of the lactic acid fermentation of vegetable juices.

The usefulness of the methods of statistical analysis is underlined by a lot of applications of CA that could be reported: in evaluation of analytical and sensory characteristics of vegetable juices ([28], [29]), in distinguishing between wines aged a different number of months ([30]).

\section{Further research}

The importance of consuming probiotic foods for the improvement of the quality of life increasingly more in the last years, being underlined by the scientific literature. The diversification of the market from this point of view could be strong correlated with the increasing of the life expectancy worldwide.

Our further researches are needed in order to optimize the level of nutrients (individually and in combination) and in the same time their influence on growth and viability of probiotics (in particular of Lactobacillus acidophilus, single strain or in combination with other probiotics), not only during fermentation but especially during the storage of the final products.

\section{Conclusions}

Different vegetable juices are suitable and alternative food matrices for the production of functional foods with Lactobacillus acidophilus LA-5, a probiotic strain which is not present in the epiphytic microbiota. Although some differences between the growths trends were determined, all the analyzed vegetables could be considered proper in order to obtain lactic acid fermented juices with a higher self-life. Application of Principal Component Analysis selected the most important parameters from analytical point of view: $\mathrm{pH}$, lactic acid, biomass and viable cells, while the Cluster Analysis divided the experimental variables into three groups.

\section{Author details}

Lavinia Claudia Buruleanu, Magda Gabriela Bratu, Iuliana Manea, Daniela Avram and Carmen Leane Nicolescu

Department of Food Engineering, Faculty of Environmental Engineering and Biotechnology, Valahia University of Targoviste, Romania

\section{Acknowledgement}

The research was funded by Executive Unit for Financing Higher Education, Research, Development and Innovation (UEFISCDI) in the frame of the Project PN-II-ID-PCE-2008-2 (ID_1359). The microorganisms were kindly provided by Chr. Hansen, Romania. 


\section{References}

[1] Granato D, Branco GF, Nazzaro F, Cruz AG, Faria JAF (2010) Functional Foods and Nondairy Probiotic Food Development: Trends, Concepts and Products. Compr. Rev. Food Sci. Food Saf. 9: 292-302.

[2] Holzapfel WH, Haberer P, Geisen R, Björkroth J, Schillinger U (2001)Taxonomy and Important Features of Probiotic Microorganisms in Food and Nutrition. Am. J. Clin. Nutr. 73(suppl): 365S-73S.

[3] Saito T (2004) Selection of Useful Probiotic Lactic Acid Bacteria from the Lactobacillus acidophilus Group and their Applications to Functional Foods. Animal Sci. J. 75:1-13.

[4] Pineiro M, Stanton C (2007) Probiotic Bacteria: Legislative Framework - Requirements to Evidence Basis. J. Nutr. 850S-853S.

[5] Kailasapathy K, Chin J (2000) Survival and Therapeutic Potential of Probiotic Organisms with Reference to Lactobacillus acidophilus and Bifidobacterium spp. Immun. Cell Biol. 78: 80-88.

[6] Karovičová J, Kohajdová Z (2003) Lactic Acid Fermented Vegetable Juices. Hort Sci.(Prague), 30 (4): 152-158.

[7] Klewicka E (2010) Antimutational Activity of Beetroot Juice. Food Technol. Biotechnol. 48(2): 229-233

[8] Altiok D (2004) Kinetic Modelling of Lactic Acid Production from Whey, Ph D Thesis, Izmir Institute of Technology, Turkey

[9] Kious, Jessica J. Lactobacillus and Lactic Acid Production [online]. Energy Research Undergraduate Laboratory Fellowship Program (ERULF), National Renewable Energy Laboratory, Colorado, 2000. Portable Document Format. Available from Internet: http://www.nrel.gov/docs/gen/fy01/NN0017.pdf.

[10] Agarwal L, Dutt K, Meghwanshi GK, Saxena RK (2008) Anaerobic Fermentative Production of Lactic Acid using Cheese Whey and Corn Steep Liquor. Biotechnol. Lett. 30: 631-635.

[11] Dave RI, Shah NP (1997) Viability of Yoghurt and Probiotic Bacteria in Yoghurts Made from Commercial Starter Cultures. Int. Dairy J. 7: 31-41.

[12] Amrane A (2005) Analysis of The Kinetics of Growth and Lactic Acid Production for Lactobacillus Helveticus Growing on Supplemented Whey Permeate. J. chem. technol. biotechnol. 80: 345-352.

[13] Kotzamanidis C, Roukas T, Skaracis G (2002) Optimization of Lactic Acid Production from Beet Molasses by Lactobacillus delbrueckii NCIMB 8130. World j. microbiol. biotechnol. 18: 441-448.

[14] Kim JW, Kim YS, Kyung KH (2004) Inhibitory Activity of Essential Oils of Garlic and Onion against Bacteria and Yeasts. J. food prot. 67(3): 499-504. 
[15] Kim JW, Huhi JE, Kyung SH, Kyung KH (2004) Antimicrobial Activity of Alk(En)Yl Sulfides Found in Essential Oils of Garlic and Onion. Food sci. biotechnol. 13(2): 235239.

[16] Kohajdová Y, Karovičová J, Greifová M (2007) Analytical and Organoleptic Profiles of Lactic Acid-Fermented Cucumber Juice with Addition of Onion Juice. J. food nutr. res. 46(3): 105-111.

[17] Rakin M, Baras J, Vukašinović M, Maksimović M (2004) The Examination of Parameters for Lactic Acid Fermentation and Nutritive Value of Fermented Juice of Beetroot, Carrot an Brewer's Yeast Autolysate, J. serbian chem. soc. 69 (8-9): 625-634.

[18] Luedeking R, Piret EL (1959) A Kinetic Study of the Lactic Acid Fermentation. Batch Process at Controlled pH, J. biochem. microbiol. technol. eng., 1: 393-412.

[19] Amrane A, Prigent Y (1999) Analysis of Growth and Production Coupling for Batch Cultures of Lactobacillus Helveticus with Help of Anunstructurated Model. Process biochemistry, 34: 1-10.

[20] Lu Z, Fleming HP, McFeeters RF (2002) Effects of Fruit Size on Fresh Cucumber Composition and the Chemical and Physical Consequences of Fermentation. J. food sci. 67(8): 2934-2939.

[21] Yoon KY, Woodams EE, Hang YD (2005) Production of Probiotic Cabbage Juice by Lactic Acid Bacteria. Bioresour. technol. 97(12): 1427-1430.

[22] Rakin MB, Baras JK, Vukašinović MS (2005) Lactic Acid Fermentation in Vegetable Juices Supplemented with Different Content of Brewer's Yeast Autolysate. Acta periodica technol. 36: 71-80.

[23] Dave RI (1998) Factors Affecting Viability of Yoghurt and Prbiotic Bacteria in Commercial Starter Cultures. PhD thesis, Victoria University of Technology, Werribee Campus, Victoria, Australia.

[24] Jang KI, Lee HG (2008) Influence of Acetic Acid Solution on Heat Stability of L-Ascorbic Acid. Food sci. biotechnol. 17: 637-641.

[25] Ding WK, Shah NP (2008) Survival of Free and Microencapsulated Probiotic Bacteria in Orange and Apple Juices. Int. food res. J. 15: 219-232.

[26] Lourens-Hattingh A, Viljoen BC (2001) Yogurt as Probiotic Carrier Food. Int. dairy j. 11: $1-17$.

[27] Bezkorovainy A. (2001) Probiotics: Determinant of Survival and Growth in the Gut. Am. j. clin. nutr. 73(suppl): 399S-405S.

[28] Bari MR, Ashrafi R, Alizade M, Rofegarineghad L. (2009) Effects of Different Contents of Yogurt Starter/Probiotic Bacteria, Storage Time and Different Concentration of Cysteine on the Microflora Characteristics of Bio-yogurt. Res. j. biol. sci. 4: 137-142.

[29] Karovičová J, Kohajdová Z (2002) The Use of PCA, FA, CA for Evaluation of Vegetable Juices Processed by Lactic Acid Fermentation. Czech j. food sci. 20: 135-143.

[30] Kohajdová Z, Karovičová J. (2004) Optimisation of Method of Fermentation of Cabbage Juice. Czech j. food sci. 22: 39-50. 
[31] Li Z, Pan QH, Jin ZM, He JJ, Liang NN, Duan CQ (2009) Evolution of 49 Phenolic Compounds in Shortly-Aged Red Wines Made from Cabernet Gernischt (Vitis vinifera L. cv.). Food sci. biotechnol. 18: 1001-1012. 